\title{
Modeling and Fault Diagnosis of Interturn Short Circuit for Five-Phase Permanent Magnet Synchronous Motor
}

\author{
Jian-wei Yang, Man-feng Dou, and Zhi-yong Dai \\ School of Automation, Northwestern Polytechnical University, Xi'an 710072, China \\ Correspondence should be addressed to Jian-wei Yang; yangjianwei100@hotmail.com
}

Received 1 June 2015; Revised 28 August 2015; Accepted 15 September 2015

Academic Editor: Ahmed F. Zobaa

Copyright (C) 2015 Jian-wei Yang et al. This is an open access article distributed under the Creative Commons Attribution License, which permits unrestricted use, distribution, and reproduction in any medium, provided the original work is properly cited.

\begin{abstract}
Taking advantage of the high reliability, multiphase permanent magnet synchronous motors (PMSMs), such as five-phase PMSM and six-phase PMSM, are widely used in fault-tolerant control applications. And one of the important fault-tolerant control problems is fault diagnosis. In most existing literatures, the fault diagnosis problem focuses on the three-phase PMSM. In this paper, compared to the most existing fault diagnosis approaches, a fault diagnosis method for Interturn short circuit (ITSC) fault of five-phase PMSM based on the trust region algorithm is presented. This paper has two contributions. (1) Analyzing the physical parameters of the motor, such as resistances and inductances, a novel mathematic model for ITSC fault of five-phase PMSM is established. (2) Introducing an object function related to the Interturn short circuit ratio, the fault parameters identification problem is reformulated as the extreme seeking problem. A trust region algorithm based parameter estimation method is proposed for tracking the actual Interturn short circuit ratio. The simulation and experimental results have validated the effectiveness of the proposed parameter estimation method.
\end{abstract}

\section{Introduction}

Owing to high torque-to-current ratio, large power-to-weight ratio, high efficiency, high-power factor, high fault tolerance, robustness, and so forth, multiphase PMSMs have been paid more attention in high-power and high-reliability applications [1-3]. Compared with the traditional three-phase PMSM, with the added phase number, the fault tolerance of the multiphase PMSM is enhanced, and thus the reliability of the multiphase PMSM is improved. Therefore, multiphase PMSMs are widely used in fault-tolerant control systems $[4,5]$.

Fault diagnosis is the foundation of the fault-tolerant control of the electrical machines. In PMSMs, the usual faults include electrical faults, mechanical faults, and magnetic faults [6]. In electrical faults, short circuit faults form $21 \%$ of the faults occurring in electrical machines. The stator winding ITSC fault is the commonest short circuit fault in PMSMs. It always occurs due to insulation failures but develops into more serious faults very quickly [7]. So it is meaningful to research the effective fault diagnosis methods of stator winding interturn short circuit for PMSMs.
The current existing detection and diagnosis methods of ITSC fault can be commonly divided into off-line methods and on-line methods [8]. Compared to the off-line methods, in on-line methods, the PMSMs do not have to be taken out of service and predicting health condition and detecting faults at an incipient stage are made easier [9]. In recent years, with the application of neural network, fuzzy logic and particle swarm optimization (PSO), the artificial intelligence (AI) online fault detection, and diagnosis methods have drawn the attention of many authors [10]. The AI methods improve the robustness and efficiency of the fault diagnosis and have no need to interpret the collected data in relation to the occurring fault.

In some AI fault detection and diagnosis methods, such as literature [11], in order to detect and diagnose the severity of the stator winding interturn short circuit fault of PMSM, a mathematical model that can describe both healthy and fault conditions is needed first. Literature [12] built power losses model of five-phase PMSM with ITSC fault and analyzed the changes in power losses due to faults occurrence by finite elements simulations. However, this fault model is not suitable for AI fault diagnosis based on parameter 
optimization. Literature [13] and literature [14] proposed two mathematical models of PMSM with ITSC fault for fault diagnosis. Unfortunately, these models are all about threephase PMSM and relatively complex. If the fault model of five-phase PMSM was built by the way shown in literature [13] and literature [14], the model would be more complex, and the calculation for the subsequent fault diagnosis based on parameter optimization would increase greatly. Thus, the efficiency of fault diagnosis would be affected. Therefore, it is meaningful to establish a relatively simple five-phase PMSM model with ITSC fault for fault diagnosis.

After the establishment of the fault model, in order to diagnose fault severity of the fault motor, the parameters associated with fault severity need to be identified. However, for the complex distribution of the parameters in the fault model, the identification problem is extremely difficult for nonlinear identification techniques. To overcome this difficulty, the fault diagnosis problem is transformed into a corresponding optimization problem and then solved by intelligent algorithm [15]. In recent years, many authors focus on PSO parameter optimization to deal with this problem, such as that shown in literature [16] and literature [17]. PSO is an evolution computation technique based on swarm intelligent methodology. PSO is initialized as a swarm of arbitrary particles (arbitrary solution), and then the optimal solution is discovered by iteration. However, the PSO algorithm creates the problems of partial convergence and precocious convergence when the particles' diversity is decreasing. Therefore, finding a better parameter optimization algorithm for fivephase PMSM fault diagnosis is essential.

In this paper, relatively simple mathematics models of the five-phase PMSM under both healthy and ITSC fault situations are established, respectively. Furthermore, a novel fault diagnosis method of ITSC based on the trust region algorithm is proposed for five-phase PMSM. With the aid of the trust region algorithm which is global convergence, the interturn short circuit ratio $\mu$ is estimated with a short time transient. The simulation and experimental results have validated both the correction of the established models and the effectiveness of the proposed parameter estimation method.

\section{Model Analysis}

2.1. Five-Phase PMSM Healthy Model. In order to establish the healthy model of five-phase PMSM, without loss of generality, the following assumptions are as follows:

(1) The magnetic circuit is linear. It is, in turn, that the magnetic circuit is not saturation.

(2) The stator winding current is sinusoidal, symmetrical, and without harmonics. The air gap magneto motive force (MMF) is sinusoidal.

(3) The rotor MMF is sinusoidal and the slot effect is neglected.

(4) The five-phase PMSM is nonsalient pole structure.

(5) Eddy currents and hysteresis losses are negligible.

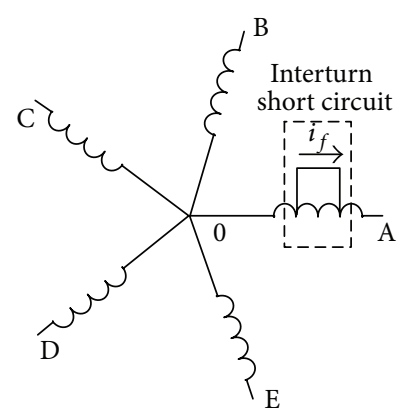

Figure 1: The schematic of five-phase PMSM with interturn short fault.

With these assumptions, the five-phase PMSM model can be provided by

$$
\begin{aligned}
& U_{s}=R_{s} I_{s}+p \psi_{s}, \\
& \psi_{s}=L_{s} I_{s}+\psi_{m}, \\
& T_{e}=\frac{\partial W}{\partial \theta}=P\left[\frac{1}{2} I_{s}^{T} \frac{\partial L_{s}}{\partial \theta} I_{s}+I_{s} \frac{\partial \psi_{m}}{\partial \theta}\right] .
\end{aligned}
$$

Equation (1) is the voltage balance equation, (2) is the flux equation, and (3) is the torque equation, where the stator phase voltage vector $U_{s}=\left[\begin{array}{lllll}u_{a} & u_{b} & u_{c} & u_{d} & u_{e}\end{array}\right]^{T}$; the stator phase current vector $I_{s}=\left[\begin{array}{lllll}i_{a} & i_{b} & i_{c} & i_{d} & i_{e}\end{array}\right]^{T}$; the stator winding resistance $R_{s}=r_{s} \times I_{5 \times 5}$; the stator flux vector $\psi_{s}=\left[\begin{array}{llllll}\psi_{a} & \psi_{b} & \psi_{c} & \psi_{d} & \psi_{e}\end{array}\right]^{T}$; the rotor flux vector $\psi_{m}=$

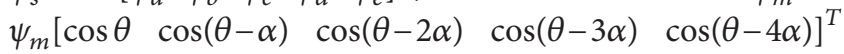
( $\theta$ is the rotor electrical angle and $\alpha=72^{\circ}$ ); $L_{s}$ is the stator inductance matrix; $p=d / d t$ is the differential operator; $P$ is the number of pole pairs; and $T_{e}$ is the electromagnetic torque.

Because of adding two-phase windings, compared to traditional PMSM, the stator inductance matrix $L_{s}$ of fivephase PMSM is more complex and it can be represented by

$$
L_{s}=\left[\begin{array}{ccccc}
L_{m} & M_{a b} & M_{a c} & M_{a d} & M_{a e} \\
M_{a b} & L_{m} & M_{b c} & M_{b d} & M_{b e} \\
M_{a c} & M_{b c} & L_{m} & M_{c d} & M_{c e} \\
M_{a d} & M_{b d} & M_{c d} & L_{m} & M_{d e} \\
M_{a e} & M_{b e} & M_{c e} & M_{d e} & L_{m}
\end{array}\right]
$$

where $L_{m}$ is the self-inductance of phase winding A (B, C, $\mathrm{D}$, and $\mathrm{E})$ and $M_{a b(c, d, e)}$ is the mutual- inductance between phase windings $\mathrm{A}$ and $\mathrm{B}(\mathrm{C}, \mathrm{D}$, and $\mathrm{E})$. Actually, the mutualinductances can be expressed by $M_{a b}=L_{m} \cos \alpha, M_{a c}=$ $L_{m} \cos 2 \alpha, M_{a d}=L_{m} \cos 3 \alpha$, and $M_{a e}=L_{m} \cos 4 \alpha$.

2.2. Five-Phase PMSM Fault Model. Without loss of generality, assume that phase winding A causes ITSC fault and the rest of the phase windings is in healthy state. The fivephase PMSM with ITSC is shown in Figure 1. Note that a short circuit loop current $i_{f}$, which gives birth to braking torque, is produced in phase winding A. And thus the braking 


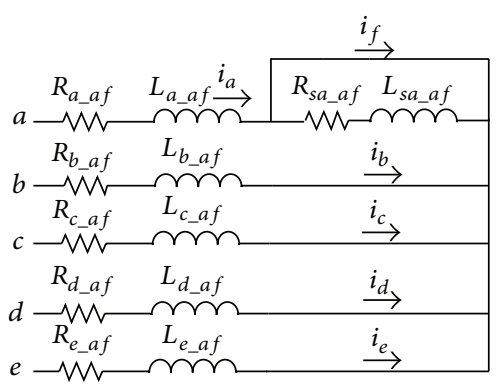

FIGURE 2: The equivalent circuit of five-phase PMSM with interturn short circuit fault.

torque affects the motor performance seriously. Besides, the effective turns number of phase winding $\mathrm{A}$ is reduced, and the values of the phase winding resistance, the self-inductance, the mutual-inductance, and the flux linkage are all changed accordingly.

In the ITSC fault model of five-phase PMSM, one of the most important parameters is the interturn short circuit ratio $\mu$, which is defined as the ratio of the shorted turns number to the total turns number. When the ITSC fault occurs in phase winding $\mathrm{A}$, depending on the physical relationship of the windings, the equivalent circuit of five-phase PMSM with ITSC fault is shown in Figure 2, where $R_{a(b, c, d, e) \_f}$ is the resistance of phase winding $\mathrm{A}(\mathrm{B}, \mathrm{C}, \mathrm{D}$, and $\mathrm{E}) ; R_{\text {sa_af }}$ is the short circuit winding resistance; $L_{a(b, c, d, e) \_a f}$ is the selfinductance of phase winding $\mathrm{A}(\mathrm{B}, \mathrm{C}, \mathrm{D}$, and $\mathrm{E}) ; L_{\text {sa af }}$ is the self-inductance of the short circuit winding; $L_{m}$ is the self-inductance of phase winding under normal conditions. Actually, the resistance and the inductances can be expressed by

$$
\begin{aligned}
R_{a \_a f} & =(1-\mu) R_{s}, \\
R_{b \_a f} & =R_{c \_a f}=R_{d \_a f}=R_{e a f}=R_{s}, \\
R_{s a \_a f} & =\mu R_{s}, \\
L_{a_{-a f}} & =(1-\mu)^{2} L_{m}, \\
L_{\text {sa_af }} & =\mu^{2} L_{m}, \\
L_{b \_a f} & =L_{c a f f}=L_{d \_a f}=L_{e \_a f}=L_{m} .
\end{aligned}
$$

Besides, there are also three kinds of mutual-inductances existing. The first is the mutual- inductance $M_{a b(c, d, e) \text { af }}$ between the remaining normal winding of phase $\mathrm{A}$ and other phase (B, C, D, and E) windings, where $M_{a b(c, d, e) a f}=(1-$ r) $M_{a b(c, d, e)}$. The second is the mutual-inductance $M_{\text {asaaf }}$ between the remaining normal winding of phase $\mathrm{A}$ and the short circuit winding of phase $\mathrm{A}$, where $M_{\text {asa af }}=(1-\mu) \mu L_{m}$. The third is the mutual-inductance $M_{s a b(c, d, e) \text { af }}$ between the short circuit winding of phase $\mathrm{A}$ and other phase (B, C, D, and E) windings, where $M_{s a b(c, d, e) a f}=\mu M_{a b(c, d, e)}$. Since the phase windings $\mathrm{B}, \mathrm{C}, \mathrm{D}$, and $\mathrm{E}$ are healthy, the mutual-inductances of the phase windings $\mathrm{B}, \mathrm{C}, \mathrm{D}$, and $\mathrm{E}$ remain the values of the healthy model.
When phase winding A causes ITSC fault, the fluxes between the windings and the rotor can be derived as

$$
\begin{aligned}
& \psi_{a a f}=(1-\mu) \psi_{m} \cos \theta, \\
& \psi_{b a f}=\psi_{m} \cos (\theta-\alpha), \\
& \psi_{c a f f}=\psi_{m} \cos (\theta-2 \alpha), \\
& \psi_{\text {daf }}=\psi_{m} \cos (\theta-3 \alpha), \\
& \psi_{e a f}=\psi_{m} \cos (\theta-4 \alpha), \\
& \psi_{\text {saaf }}=\mu \psi_{m} \cos \theta .
\end{aligned}
$$

According to the equivalent circuit and the analysis above, the voltage balance equation renders as

$$
\begin{aligned}
& V_{a}=R_{a \_a f} i_{a}+L_{a \_a f} \frac{d i_{a}}{d t}+M_{a b \_a f} \frac{d i_{b}}{d t}+M_{a c \_a f} \frac{d i_{c}}{d t} \\
& +M_{a d \_a f} \frac{d i_{d}}{d t}+M_{a e \_a f} \frac{d i_{e}}{d t} \\
& +M_{\text {asa } a f} \frac{d\left(i_{a}-i_{f}\right)}{d t}+\frac{d \psi_{a \_a f}}{d t}, \\
& V_{b}=R_{b \_a f} i_{b}+L_{b \_a f} \frac{d i_{b}}{d t}+M_{a b a f} \frac{d i_{a}}{d t}+M_{b c a f} \frac{d i_{c}}{d t} \\
& +M_{b d \_a f} \frac{d i_{d}}{d t}+M_{b e \_a f} \frac{d i_{e}}{d t} \\
& +M_{b s a a f} \frac{d\left(i_{a}-i_{f}\right)}{d t}+\frac{d \psi_{b \_a f}}{d t}, \\
& V_{c}=R_{c \_a f} i_{c}+L_{c \_a f} \frac{d i_{c}}{d t}+M_{a c \_a f} \frac{d i_{a}}{d t}+M_{b c \_a f} \frac{d i_{b}}{d t} \\
& +M_{c d \_a f} \frac{d i_{d}}{d t}+M_{c e \_a f} \frac{d i_{e}}{d t} \\
& +M_{c s a \_a f} \frac{d\left(i_{a}-i_{f}\right)}{d t}+\frac{d \psi_{c \_a f}}{d t}, \\
& V_{d}=R_{d \_a f} i_{d}+L_{d \_a f} \frac{d i_{d}}{d t}+M_{a d \_a f} \frac{d i_{a}}{d t}+M_{b d \_a f} \frac{d i_{b}}{d t} \\
& +M_{c d \_a f} \frac{d i_{c}}{d t}+M_{d e \_a f} \frac{d i_{e}}{d t} \\
& +M_{d s a a f} \frac{d\left(i_{a}-i_{f}\right)}{d t}+\frac{d \psi_{d a f}}{d t}, \\
& V_{e}=R_{e-a f} i_{e}+L_{e-a f} \frac{d i_{e}}{d t}+M_{a e-a f} \frac{d i_{a}}{d t}+M_{b e-a f} \frac{d i_{b}}{d t} \\
& +M_{c e-a f} \frac{d i_{c}}{d t}+M_{d e \_a f} \frac{d i_{d}}{d t} \\
& +M_{\text {esa_af }} \frac{d\left(i_{a}-i_{f}\right)}{d t}+\frac{d \psi_{e a f}}{d t},
\end{aligned}
$$




$$
\begin{aligned}
& 0=R_{\text {sa af }}\left(i_{a}-i_{f}\right)+L_{s a \_a f} \frac{d\left(i_{a}-i_{f}\right)}{d t}+M_{a s a a f} \frac{d i_{a}}{d t} \\
& +M_{s a b \_a f} \frac{d i_{b}}{d t}+M_{s a c \_a f} \frac{d i_{c}}{d t}+M_{s a d \_a f} \frac{d i_{d}}{d t} \\
& +M_{\text {sae } a f} \frac{d i_{e}}{d t}+\frac{d \psi_{\text {sa_af }}}{d t} \text {. }
\end{aligned}
$$

$$
V_{a f}=R_{a f} I_{a f}+L_{a f} \frac{d I_{a f}}{d t}+\frac{d \psi_{a f}}{d t}
$$

where

$$
\begin{aligned}
& V_{a f}= {\left[\begin{array}{llllll}
V_{a} & V_{b} & V_{c} & V_{d} & V_{e} & 0
\end{array}\right]^{T}, } \\
& I_{a f}= {\left[\begin{array}{llllll}
i_{a} & i_{b} & i_{c} & i_{d} & i_{e} & i_{f}
\end{array}\right]^{T}, } \\
& R_{a f}= {\left[\begin{array}{cccccc}
R_{s} & 0 & 0 & 0 & 0 & -\mu R_{s} \\
0 & R_{s} & 0 & 0 & 0 & 0 \\
0 & 0 & R_{s} & 0 & 0 & 0 \\
0 & 0 & 0 & R_{s} & 0 & 0 \\
0 & 0 & 0 & 0 & R_{s} & 0 \\
\mu R_{s} & 0 & 0 & 0 & 0 & -\mu R_{s}
\end{array}\right], } \\
& L_{a f}=\left[\begin{array}{cccccc}
L_{m} & M_{a b} & M_{a c} & M_{a d} & M_{a e} & -\mu L_{m} \\
M_{a b} & L_{m} & M_{a b} & M_{a c} & M_{a d} & -\mu M_{a b} \\
M_{a c} & M_{a b} & L_{m} & M_{a b} & M_{a c} & -\mu M_{a c} \\
M_{a d} & M_{a c} & M_{a b} & L_{m} & M_{a b} & -\mu M_{a d} \\
M_{a e} & M_{a d} & M_{a c} & M_{a b} & L_{m} & -\mu M_{a e} \\
\mu L_{m} & \mu M_{a b} & \mu M_{a c} & \mu M_{a d} & \mu M_{a e} & -\mu^{2} L_{m}
\end{array}\right], \\
& {\left[\begin{array}{ccccc}
\cos \theta & \cos (\theta-\alpha) & \cos (\theta-2 \alpha) & \cos (\theta-3 \alpha) \cos (\theta-4 \alpha) \mu \cos \theta]^{T} .
\end{array} .\right.}
\end{aligned}
$$
is

The electromagnetic torque equation of five-phase PMSM

$$
\begin{aligned}
T_{e} & =\frac{\partial W}{\partial \theta}=p\left[\frac{1}{2} I_{a f}^{T} \frac{\partial L_{a f}}{\partial \theta} I_{a f}+I_{a f} \frac{\partial \psi_{a f}}{\partial \theta}\right] \\
& =p\left[I_{a f} \frac{\partial \psi_{a f}}{\partial \theta}\right] .
\end{aligned}
$$

The mechanical motion equation of five-phase PMSM is

$$
T_{e}-T_{L}=\frac{J d \omega}{d t}+B \omega
$$

where $T_{e}$ is the electromagnetic torque; $T_{L}$ is the load torque; $J$ is the rotational inertia; $B$ is the viscous friction coefficient; $\omega$ is the mechanical angular velocity.

\section{Fault Diagnosis}

3.1. Trust Region Algorithm. Trust region algorithm is a method for the extreme seeking. The method sets a trust region radius as the upper bound of the displacement length and, with the current iteration point as the center, determines a closed spherical region named trust region. By solving the optimal point of the quadratic approximation model to determine the candidate displacement, the nonlinear extreme problem is transformed into the extreme problem of solving the approximation quadratic model of the objective function within the trust region [18, 19]. If the candidate displacement enables the sufficient reduction to the objective function, the candidate displacement is adopted to be the new displacement and simultaneously maintains or expands the trust region radius for a new round of iteration. Otherwise, it indicates the approximate degree of the quadratic model and the objective function is unsatisfactory, the trust region radius should be reduced, and the extreme problem of the approximation quadratic model should be solved within the new trust region radius to obtain the new candidate displacement [20]. By the continuous iteration, the extreme optimization of nonlinear function is achieved. 
The trust region methods can be understood by a typical unconstrained minimization problem:

$$
\min _{x \in \mathbb{R}^{n}} f(x),
$$

where $f(x)$ is objective function to be minimized.

Suppose that $x_{k}$ is the $k$ th iteration, $f_{k}=f\left(x_{k}\right), g_{k}=$ $\nabla f\left(x_{k}\right)$, and $B_{k}$ is the $k$ th approximation of the Hesse Matrix $\nabla^{2} f\left(x_{k}\right)$. So the trust region subproblem is

$$
\begin{aligned}
\min & q_{k}(d)=g_{k}^{T} d+\frac{1}{2} d^{T} B_{k} d \\
\text { s.t. } & \|d\| \leq \Delta_{k},
\end{aligned}
$$

where $\Delta_{k}$ is the trust region radius and $\|\cdot\|$ is the vector norm, usually $\|\cdot\|_{2}$ or $\|\cdot\|_{\infty}$. Suppose that the optimal solution of (13) is $d_{k} ; \Delta f_{k}$ is the decreasing of the $k$ th iteration, and $\Delta f_{k}=f_{k}-$ $f\left(x_{k}+d_{k}\right) ; \Delta q_{k}$ is the predicted decreasing correspondingly, and $\Delta q_{k}=q_{k}(0)-q_{k}\left(d_{k}\right)$. Define $r_{k}$ as

$$
r_{k}=\frac{\Delta f_{k}}{\Delta q_{k}} .
$$

Generally, $\Delta q_{k}>0$. So if $r_{k}<0, \Delta f_{k}<0, x_{k}+d_{k}$ will not be the next iteration point. To solve the subproblem, the trust region radius needs to be reduced. If the value of $r_{k}$ is closed to 1 , it indicates that the quadratic model is a good approximation for the objective function within the trust region, $x_{k+1}:=x_{k}+$ $d_{k}$ can be used as the new iteration point, and meantime the trust region radius can be increased in the next iteration. For other cases, the trust region radius remains unchanged.

3.2. Fault Parameter Identification. In order to diagnose the fault severity of the fault motor, the interturn short circuit ratio $\mu$ needs to be identified based on the fault model. Because of the complex distribution of the parameter in the fault model, the identification problem is extremely difficult for nonlinear identification techniques. To overcome the difficulty, the fault diagnosis problem is first transformed into a corresponding optimization problem and then solved using trust region algorithm. Because of its simplicity, global convergence, and computational efficiency, trust region algorithm has been used extensively to solve a broad range of optimization problems. Numerous applications have applied trust region algorithm for parameter tuning and identification. The applications based on trust region algorithm are not limited by model structures, as are many traditional identification algorithms. As long as the model performs differently with different parameters, which is almost always true, trust region algorithm will be able to identify the unknown parameters in the models.

The principle of fault parameter (the interturn short circuit ratio $\mu$ ) identification for five-phase PMSM under ITSC fault is as shown in Figure 3.

To begin with, give an arbitrary constant $\widehat{\mu}(0) \in(0,1)$ as the initial estimation value of the interturn short circuit ratio for the five-phase fault PMSM model. Meanwhile, sample both the five-phase PMSM drive voltage $V$ and the phase currents $i$ from the actual PMSM. And then, a reference model of the five-phase PMSM with ITSC fault is established as (7), and its drive voltage is the same as the actual PMSM.

Afterwards, to diagnose the fault severity of the five-phase PMSM, or in other words, to identify the fault parameter (the interturn short circuit ratio $\mu$ ) by trust region algorithm, a quadratic fitness function is introduced as

$$
f(\widehat{\mu})=\sum_{n=1}^{5}\left(i_{n}-i_{n}^{*}\right)^{2},
$$

where $i$ and $i^{*}$ are the phase current of the actual PMSM and reference model, respectively. In fact, the objective function is related to the parameters the interturn short circuit ratio $u$ and its estimation $\widehat{\mu}$. It can be proved that the objective function is equal to zero if and only if the actual interturn short circuit ratio is equal to its estimation.

At last, use the trust region algorithm to seek the interturn short circuit ratio estimation value $\widehat{\mu}$ such that the fitness function achieves its minimum value zero. The specific steps of the trust region algorithm parameter identification can be realized as follows. In the process of parameter optimization, the gradient and the approximation of the Hesse Matrix for the quadratic fitness function are calculated, respectively, as (16) and (17).

Step 0 . Select the initial parameters, where $0 \leq \eta_{1}<\eta_{2}<1$, $0 \leq \tau_{1}<1<\tau_{2}$, and $0 \leq \varepsilon \ll 1$. Consider $\widehat{\mu}(0) \in(0,1)$. The upper limit of the trust region radius is $\bar{\Delta}, \bar{\Delta}>0$, and the initial trust region radius is $\Delta_{0}, \Delta_{0} \in(0, \bar{\Delta})$. Set $k:=0$.

Step 1. Calculate $g_{k}$ as shown in (16); if $\left\|g_{k}\right\| \leq \varepsilon$, stop the iteration

$$
\begin{aligned}
& g_{k}=\nabla f(\widehat{\mu})
\end{aligned}
$$

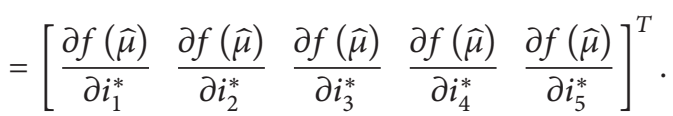

Step 2. Solve the trust region subproblem of the objective function (15), and the solution is $d_{k}$.

Step 3. Calculate the value of $r_{k}$ as (14), and in the calculation of $r_{k}, q_{k}$ is calculated as shown in (14), where $B_{k}$ is the $k$ th approximation of the Hesse Matrix, as shown in

$$
\begin{aligned}
B_{k} & =\nabla^{2} f(\widehat{\mu}) \\
= & {\left[\begin{array}{lllll}
\frac{\partial^{2} f(\widehat{\mu})}{\partial^{2} i_{1}^{*}} & \frac{\partial^{2} f(\widehat{\mu})}{\partial i_{1}^{*} \partial i_{2}^{*}} & \frac{\partial^{2} f(\widehat{\mu})}{\partial i_{1}^{*} \partial i_{3}^{*}} & \frac{\partial^{2} f(\widehat{\mu})}{\partial i_{1}^{*} \partial i_{4}^{*}} & \frac{\partial^{2} f(\widehat{\mu})}{\partial i_{1}^{*} \partial i_{5}^{*}} \\
\frac{\partial^{2} f(\widehat{\mu})}{\partial i_{2}^{*} \partial i_{1}^{*}} & \frac{\partial^{2} f(\widehat{\mu})}{\partial^{2} i_{2}^{*}} & \frac{\partial^{2} f(\widehat{\mu})}{\partial i_{2}^{*} \partial i_{3}^{*}} & \frac{\partial^{2} f(\widehat{\mu})}{\partial i_{2}^{*} \partial i_{4}^{*}} & \frac{\partial^{2} f(\widehat{\mu})}{\partial i_{2}^{*} \partial i_{5}^{*}} \\
\frac{\partial^{2} f(\widehat{\mu})}{\partial i_{3}^{*} \partial i_{1}^{*}} & \frac{\partial^{2} f(\widehat{\mu})}{\partial i_{3}^{*} \partial i_{2}^{*}} & \frac{\partial^{2} f(\widehat{\mu})}{\partial^{2} i_{3}^{*}} & \frac{\partial^{2} f(\widehat{\mu})}{\partial i_{3}^{*} \partial i_{4}^{*}} & \frac{\partial^{2} f(\widehat{\mu})}{\partial i_{3}^{*} \partial i_{5}^{*}} \\
\frac{\partial^{2} f(\widehat{\mu})}{\partial i_{4}^{*} \partial i_{1}^{*}} & \frac{\partial^{2} f(\widehat{\mu})}{\partial i_{4}^{*} \partial i_{2}^{*}} & \frac{\partial^{2} f(\widehat{\mu})}{\partial i_{4}^{*} \partial i_{3}^{*}} & \frac{\partial^{2} f(\widehat{\mu})}{\partial^{2} i_{4}^{*}} & \frac{\partial^{2} f(\widehat{\mu})}{\partial i_{4}^{*} \partial i_{5}^{*}} \\
\frac{\partial^{2} f(\widehat{\mu})}{\partial i_{5}^{*} \partial i_{1}^{*}} & \frac{\partial^{2} f(\widehat{\mu})}{\partial i_{5}^{*} \partial i_{2}^{*}} & \frac{\partial^{2} f(\widehat{\mu})}{\partial i_{5}^{*} \partial i_{3}^{*}} & \frac{\partial^{2} f(\widehat{\mu})}{\partial i_{5}^{*} \partial i_{4}^{*}} & \frac{\partial^{2} f(\widehat{\mu})}{\partial^{2} i_{5}^{*}}
\end{array}\right] . }
\end{aligned}
$$




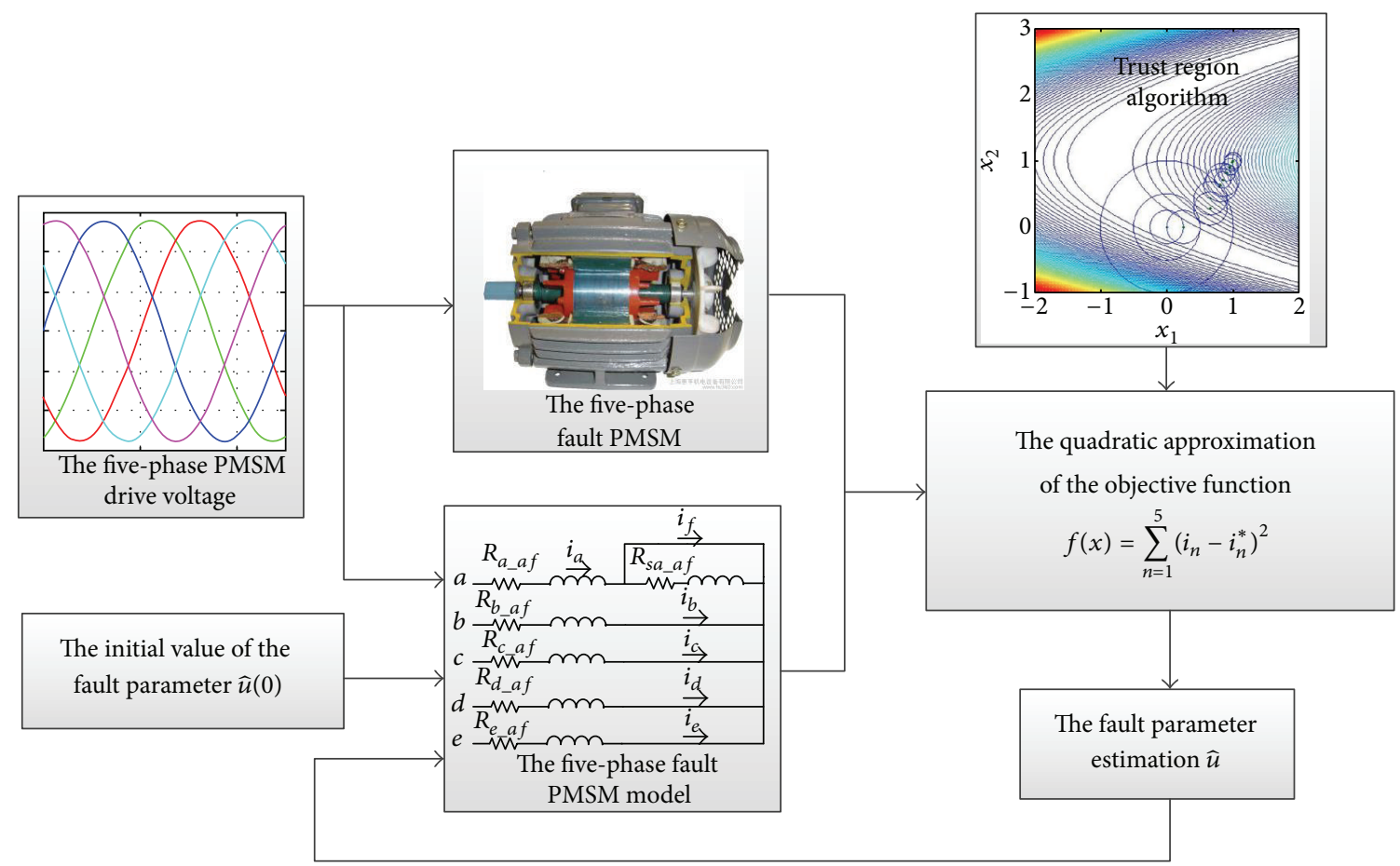

FIgURE 3: The block diagram of fault parameter identification based on trust region algorithm.

Step 4. Correct trust region radius as follows:

$$
\Delta_{k+1}:= \begin{cases}\tau_{1} \Delta_{k}, & \text { if } r_{k} \leq \eta_{1}, \\ \Delta_{k}, & \text { if } \eta_{1}<r_{k} \leq \eta_{2}, \\ \min \left\{\tau_{2} \Delta_{k}, \bar{\Delta}\right\}, & \text { if } r_{k} \geq \eta_{2},\left\|d_{k}\right\|=\Delta_{k} .\end{cases}
$$

Step 5. If $r_{k}>\eta_{1}$, set $\widehat{\mu}_{k+1}:=\widehat{\mu}_{k}+d_{k}, B_{k}:=B_{k+1}, k:=k+1$, and go to Step 1; else set $\widehat{\mu}_{k+1}:=\widehat{\mu}_{k}, k:=k+1$, and go to Step 2 .

\section{Simulation Analysis}

In order to verify the model of the five-phase PMSM under ITSC fault and the trust region algorithm in the process of the fault parameter identification, the simulation has been done by MATLAB/Simulink. The parameters of five-phase PMSM are shown in Table 1.

Figure 4 shows the phase current waveforms in healthy state. Figures 5 and 6 show the phase current waveforms in fault state. Notice that the current of phase A (the yellow line) in fault state is significantly larger than the healthy ones. And with the increase of the fault parameter $u$, the current of phase $\mathrm{A}$ in fault state also increases. And meanwhile, the current waveforms of other phases are also affected by the fault phase A.

The parameters of five-phase PMSM for fault parameter identification based on trust region algorithm are shown in Table 2.

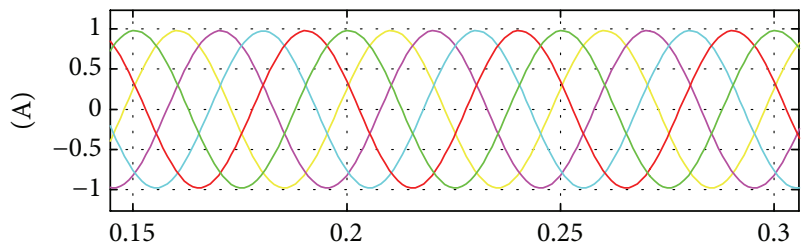

(s)

FIGURE 4: The phase current waveforms in normal state.

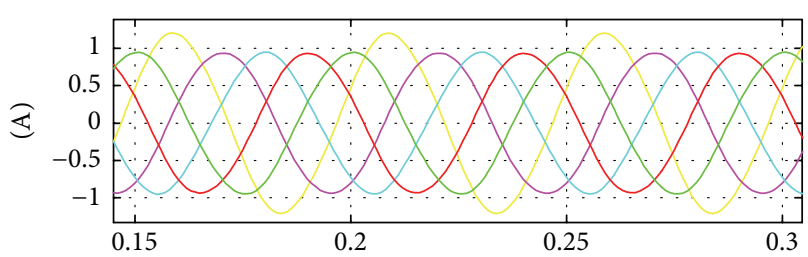

(s)

FIGURE 5: The phase current waveforms in fault state $(u=0.2)$.

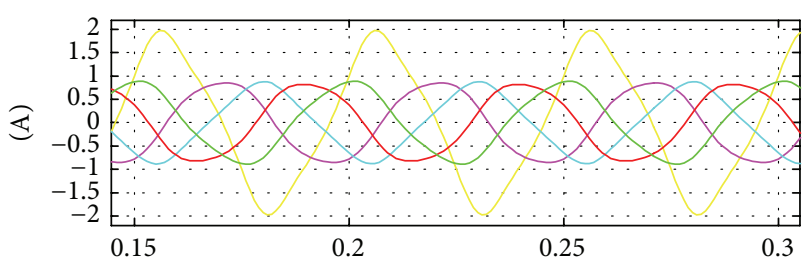

(s)

FIGURE 6: The phase current waveforms in fault state $(u=0.5)$. 


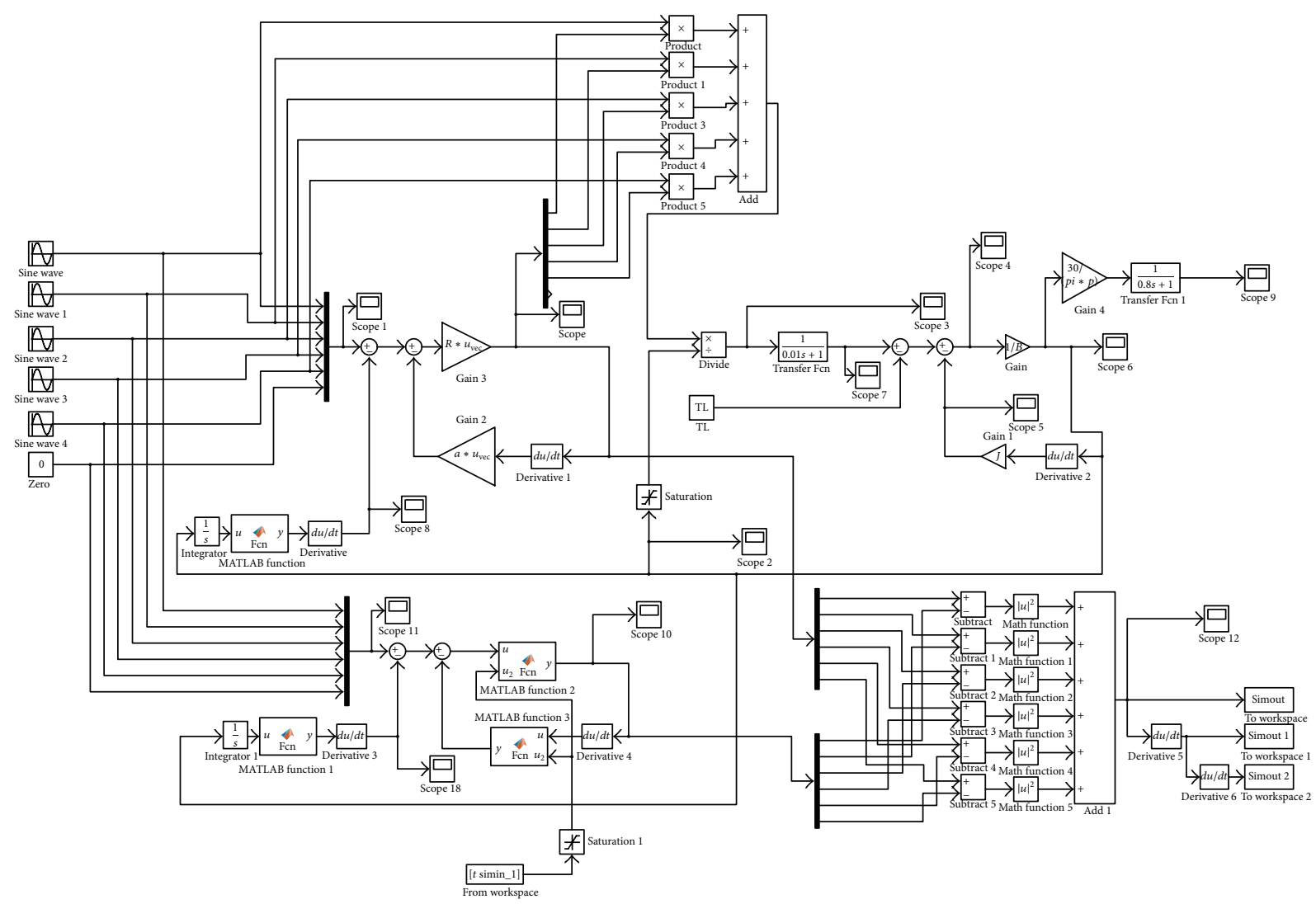

FIgURE 7: The simulation model of five-phase PMSM for fault parameter identification.

TABLE 1: Parameters of five-phase PMSM used for simulation.

\begin{tabular}{lcc}
\hline Stator winding resistance & $R_{s}$ & $17.4(\Omega)$ \\
Self-inductance of phase winding & $L_{m}$ & $4.5 e-2(\mathrm{H})$ \\
Flux amplitude & $\psi_{m}$ & $0.1827 \mathrm{~Wb}$ \\
Moment of inertia & $J$ & $0.8 e-6\left(\mathrm{kgm}^{2}\right)$ \\
Friction constant & $B$ & $1 e-3(\mathrm{Nms})$ \\
Number of pole pairs & $p$ & 4 \\
Load torque & $T_{L}$ & $0.4(\mathrm{Nm})$ \\
Input sinusoidal voltage amplitude & $V$ & $28(\mathrm{~V})$ \\
Input voltage frequency & $f$ & $20(\mathrm{~Hz})$ \\
\hline
\end{tabular}

The Simulink simulation model of five-phase PMSM for fault parameter identification based on trust region algorithm is shown in Figure 7.

The results of five-phase PMSM for fault parameter identification based on trust region algorithm are shown in Table 3 . The actual value of the interturn short circuit ratio $\mu$ is 0.2 ( $20 \%$ of the total turns occurring are shorted) and the initial estimation value of the interturn short circuit ratio $u^{*}$ is 0.3. After six steps of the trust region seeking calculation, the estimation value of interturn short circuit ratio $u^{*}$ converges to the actual value.

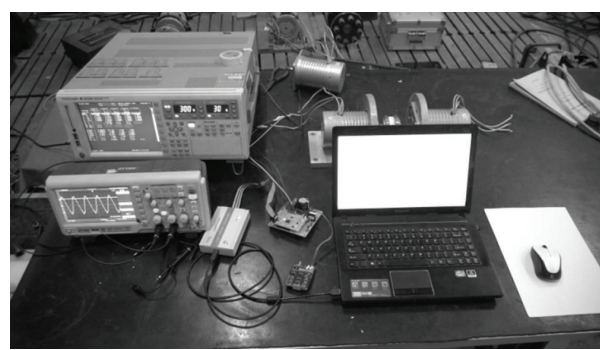

Figure 8: Experimental devices.

\section{Experimental Results}

To verify the model of the five-phase PMSM under ITSC fault and the trust region algorithm in the process of the fault parameter identification, the experiment has been done. The parameters of five-phase PMSM are the same as shown in Table 1. The experimental devices are as shown in Figure 8. Figure 9 is the phase current waveforms of the five-phase PMSM under 20\% ITSC fault in phase A. Figure 10 is the fitness function curve in optimization process under $20 \%$ ITSC fault in phase A.

Comparing the experimental results with the simulation results, it can be seen that the actual phase current waveforms 


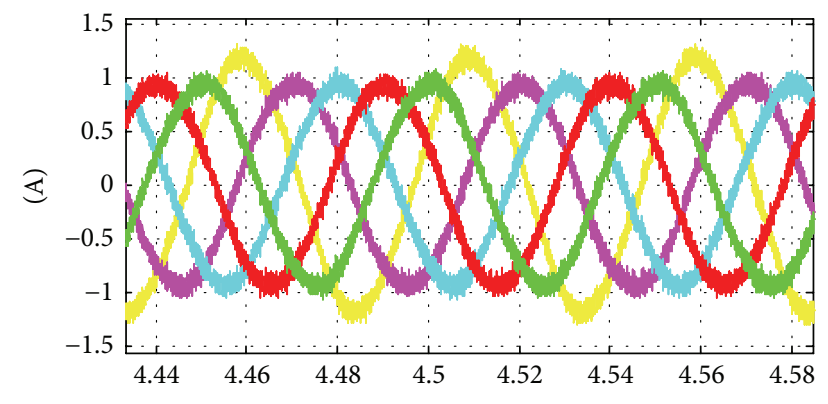

(s)

Figure 9: Phase current waveforms of the five-phase PMSM under $20 \%$ ITSC fault in phase A.

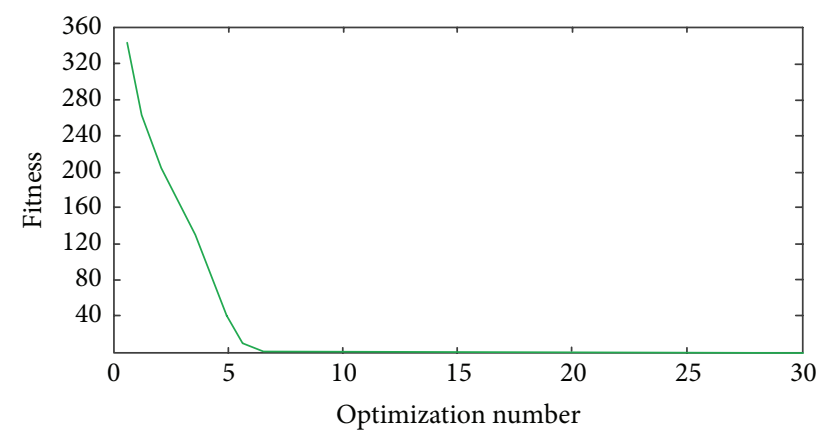

FIGURE 10: Fitness function curve in optimization process under $20 \%$ ITSC fault in phase A.

TABLE 2: Parameters of trust region algorithm.

\begin{tabular}{lc}
\hline$\eta_{1}$ & 0.1 \\
$\eta_{2}$ & 0.75 \\
$\bar{\Delta}$ & 2.0 \\
$\tau_{1}$ & 0.5 \\
$\tau_{2}$ & 2.0 \\
$\varepsilon$ & 0.1 \\
\hline
\end{tabular}

TABLE 3: Result of fault parameter identification.

\begin{tabular}{cccc}
\hline$k$ & $\Delta_{0}$ & $r_{k}$ & $u^{*}$ \\
\hline 1 & 1.0 & 0.1799 & 0.2834 \\
2 & 1.0 & 0.2072 & 0.2668 \\
3 & 1.0 & 0.2462 & 0.2502 \\
4 & 1.0 & 0.3061 & 0.2335 \\
5 & 1.0 & 0.4050 & 0.2167 \\
6 & 1.0 & 0.5298 & 0.2001 \\
\hline
\end{tabular}

are almost the same as the simulation analysis from Figures 5 and 9. The peak current values of the nonfault phases are all $1 \mathrm{~A}$ approximately in both the simulation results and the experimental results. And the peak current values of the fault phase are all about $1.2 \mathrm{~A}$ in both the simulation waveform and the experimental waveform. It proves the correction of the mathematics models built for the five-phase PMSM under both healthy and ITSC fault situations. The only difference between simulation results and experimental results is that the experimental phase current waveforms are not so smooth as shown in the simulation results. The reason is that there may be interference during the actual current sampling process, which results in the current glitch.

Figure 10 is the fitness function curve in optimization process under $20 \%$ ITSC fault in phase A. It can be seen that the value of the fitness function is close to zero at the tenth optimization. And from Table 3, it can be seen that, in the simulation, after six steps of the trust region seeking calculation, the estimation value of interturn short circuit ratio $u^{*}$ converges to the actual value. Compared to simulation results, the optimization number of the trust region seeking in the experiment is larger than the simulation shown, for the reason that the actual phase voltage and current of the motor are sampled by the voltage sensor and current sensor, and there are errors during the sampling procedure. So the optimization number is added. However, it is obvious that both the simulation and the experiment are all successful implementations of the parameter identification and prove the correctness of the proposed parameter estimation method for the fault diagnosis.

\section{Conclusions}

In this paper, the mathematics models for the five-phase PMSM under both healthy and ITSC fault situations are established, respectively. Furthermore, a novel fault diagnosis method of ITSC based on the trust region algorithm is proposed for five-phase PMSM. With the aid of the trust region algorithm, the interturn short circuit ratio $\mu$ is estimated with a short time transient. The simulation and experimental results have validated both the correction of the established models and the effectiveness of the proposed parameter estimation method.

\section{Conflict of Interests}

The authors declare that there is no conflict of interests regarding the publication of this paper.

\section{Acknowledgment}

This research was supported by the National Natural Science Foundation of China (Grant no. 51407143).

\section{References}

[1] K. D. Hoang, Y. Ren, Z.-Q. Zhu, and M. Foster, "Modified switching-table strategy for reduction of current harmonics in direct torque controlled dual-three-phase permanent magnet synchronous machine drives," IET Electric Power Applications, vol. 9, no. 1, pp. 10-19, 2015.

[2] R. Islam, M. Islam, J. Tersigni, and T. Sebastian, "Inter winding short circuit faults in permanent magnet synchronous motors used for high performance applications," in Proceedings of the 4th Annual IEEE Energy Conversion Congress and Exposition (ECCE '12), pp. 1291-1298, September 2012. 
[3] G. Vinson, M. Combacau, T. Prado, and P. Ribot, "Permanent magnets synchronous machines faults detection and identification," in Proceedings of the 38th Annual Conference on IEEE Industrial Electronics Society (IECON '12), pp. 3925-3930, Montreal, Canada, October 2012.

[4] B. G. Gu, J. H. Choi, and I. S. Jung, "A dynamic modeling and a fault detection scheme of a PMSM under an inter turn short," in Proceedings of the IEEE Vehicle Power and Propulsion Conference (VPPC '12), pp. 1074-1080, Seoul, Republic of Korea, October 2012.

[5] N. Leboeuf, T. Boileau, B. Nahid-Mobarakeh, N. Takorabet, F. Meibody-Tabar, and G. Clerc, "Effects of imperfect manufacturing process on electromagnetic performance and online interturn fault detection in PMSMs," IEEE Transactions on Industrial Electronics, vol. 62, no. 6, pp. 3388-3398, 2015.

[6] Z. Wang, J. Yang, H. Ye, and W. Zhou, "A review of permanent magnet synchronous motor fault diagnosis," in Proceedings of the IEEE Transportation Electrification Conference and Expo (ITEC Asia-Pacific '14), Beijing, China, September 2014.

[7] A. Gandhi, T. Corrigan, and L. Parsa, "Recent advances in modeling and online detection of stator interturn faults in electrical motors," IEEE Transactions on Industrial Electronics, vol. 58, no. 5, pp. 1564-1575, 2011.

[8] M. Eftekhari, M. Moallem, S. Sadri, and A. Shojaei, "Review of induction motor testing and monitoring methods for interturn stator winding faults," in Proceedings of the 21st Iranian Conference on Electrical Engineering (ICEE '13), pp. 1-6, IEEE, Mashhad, Iran, May 2013.

[9] D. Yao and H. Toliyat, "A review of condition monitoring and fault diagnosis for permanent magnet machines," in Proceedings of the IEEE Power and Energy Society General Meeting (PES '12), pp. 1-4, San Diego, Calif, USA, July 2012.

[10] M. A. Shamsi Nejad and M. Taghipour, "Inter-turn stator winding fault diagnosis and determination of fault percent in PMSM," in Proceedings of the IEEE Applied Power Electronics Colloquium (IAPEC '11), pp. 128-131, Johor Bahru, Malaysia, April 2011.

[11] F. Grouz, L. Sbita, and M. Boussak, "Particle swarm optimization based fault diagnosis for non-salient PMSM with multi-phase inter-turn short circuit," in Proceedings of the 2nd International Conference on Communications, Computing and Control Applications (CCCA '12), pp. 1-6, IEEE, Marseille, France, December 2012.

[12] H. Saavedra, J.-R. Riba, and L. Romeral, "Inter-turn fault detection in five-phase pmsms. Effects of the fault severity," in Proceedings of the 9th IEEE International Symposium on Diagnostics for Electric Machines, Power Electronics and Drives (SDEMPED '13), pp. 520-526, Valencia, Spain, August 2013.

[13] L. Romeral, J. C. Urresty, J.-R. R. Ruiz, and A. G. Espinosa, "Modeling of surface-mounted permanent magnet synchronous motors with stator winding interturn faults," IEEE Transactions on Industrial Electronics, vol. 58, no. 5, pp. 1576-1585, 2011.

[14] N. H. Obeid, T. Boileau, and B. Nahid-Mobarakeh, "Modeling and diagnostic of incipient inter-turn faults for a three phase permanent magnet synchronous motor," in Proceedings of the IEEE Industry Applications Society Annual Meeting, pp. 1-8, IEEE, Vancouver, Canada, October 2014.

[15] B.-G. Park, R.-Y. Kim, and D.-S. Hyun, "Fault diagnosis using recursive least square algorithm for permanent magnet synchronous motor drives," in Proceedings of the 8th IEEE International Conference on Power Electronics and ECCE Asia
(ICPE-ECCE '11), pp. 2506-2510, IEEE, Jeju, Republic of Korea, May-June 2011.

[16] F. Grouz, L. Sbita, and M. Boussak, "Modelling for non-salient PMSM with multi-phase inter-turn short circuit," in Proceedings of the 10th IEEE International Multi-Conference on Systems, Signals \& Devices (SSD '13), pp. 1-6, IEEE, Hammamet, Tunisia, March 2013.

[17] W. Liu, L. Liu, I.-Y. Chung, D. A. Cartes, and W. Zhang, "Modeling and detecting the stator winding fault of permanent magnet synchronous motors," Simulation Modelling Practice and Theory, vol. 27, pp. 1-16, 2012.

[18] Z. Min and S. Pingping, "Nonlinear model predictive control algorithm based on filter-trust-region method," in Proceedings of the 31st Chinese Control Conference (CCC 2012), pp. 40694074, IEEE, Hefei, China, July 2012.

[19] P. M. Moubarak, "Trust-region reflective adaptive controller for time varying systems," IET Control Theory \& Applications, vol. 9, no. 2, pp. 240-247, 2015.

[20] Y. Shu-Ping, Y. Xiu-Gui, and L. Zai-Ming, "A trust region algorithm based on general curve-linear searching direction for unconstrained optimization," in Proceedings of the 4th International Conference on Intelligent Computation Technology and Automation (ICICTA '11), pp. 328-332, Shenzhen, China, March 2011. 

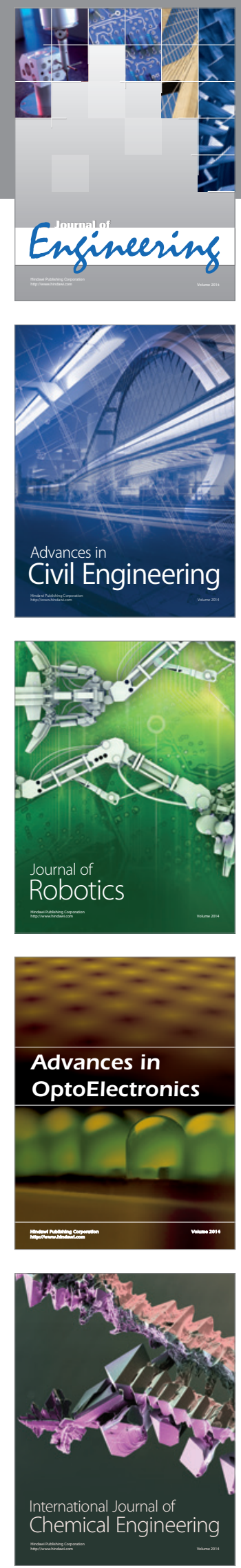

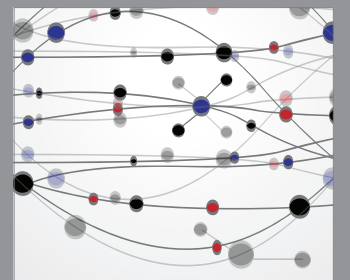

The Scientific World Journal
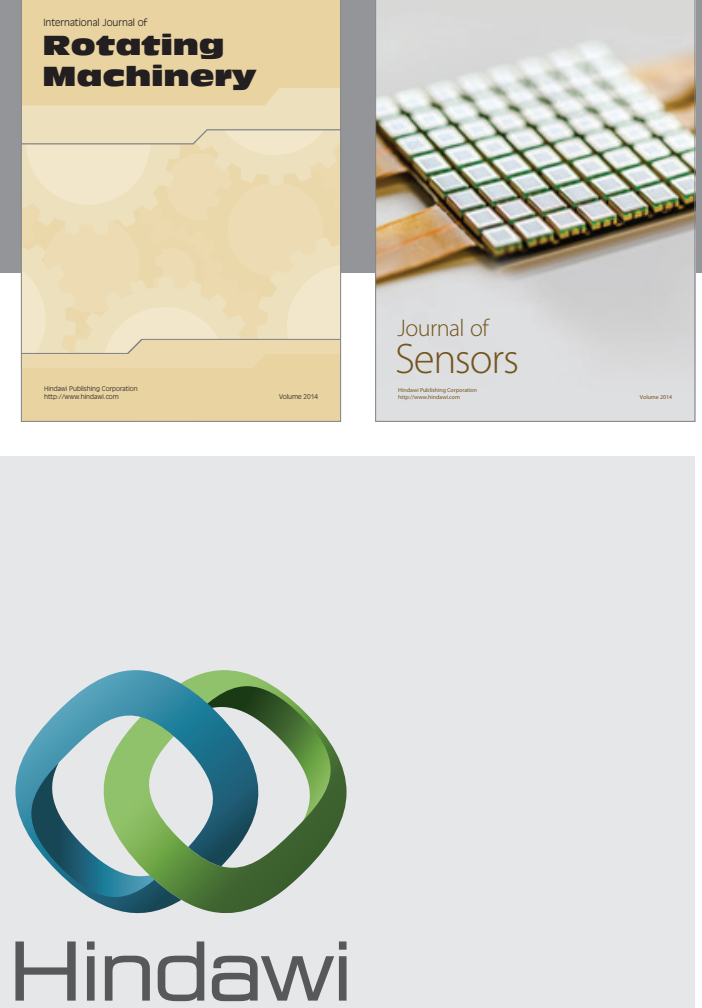

Submit your manuscripts at http://www.hindawi.com
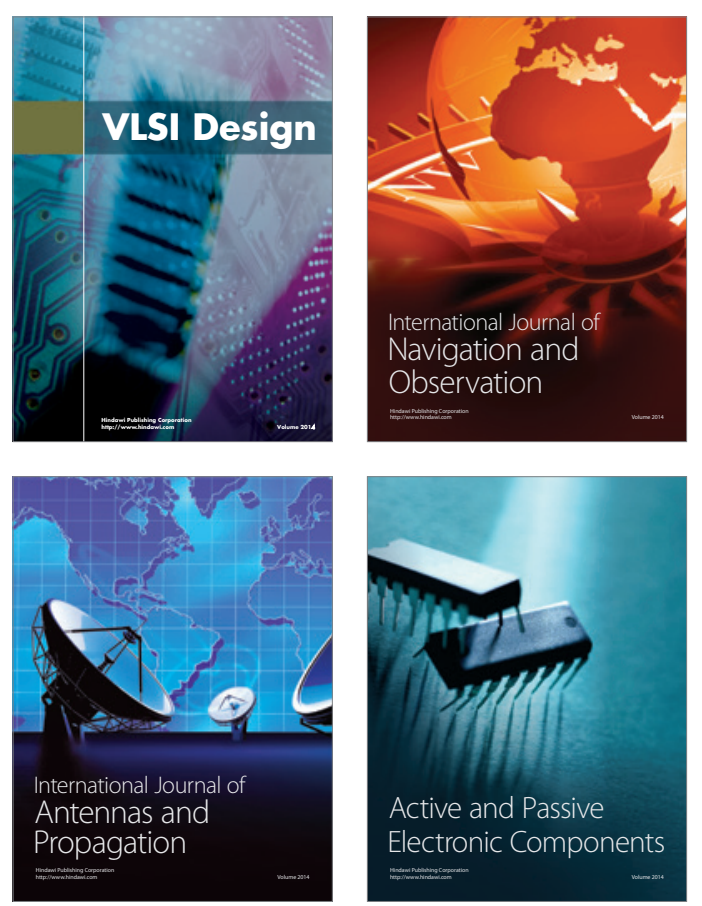
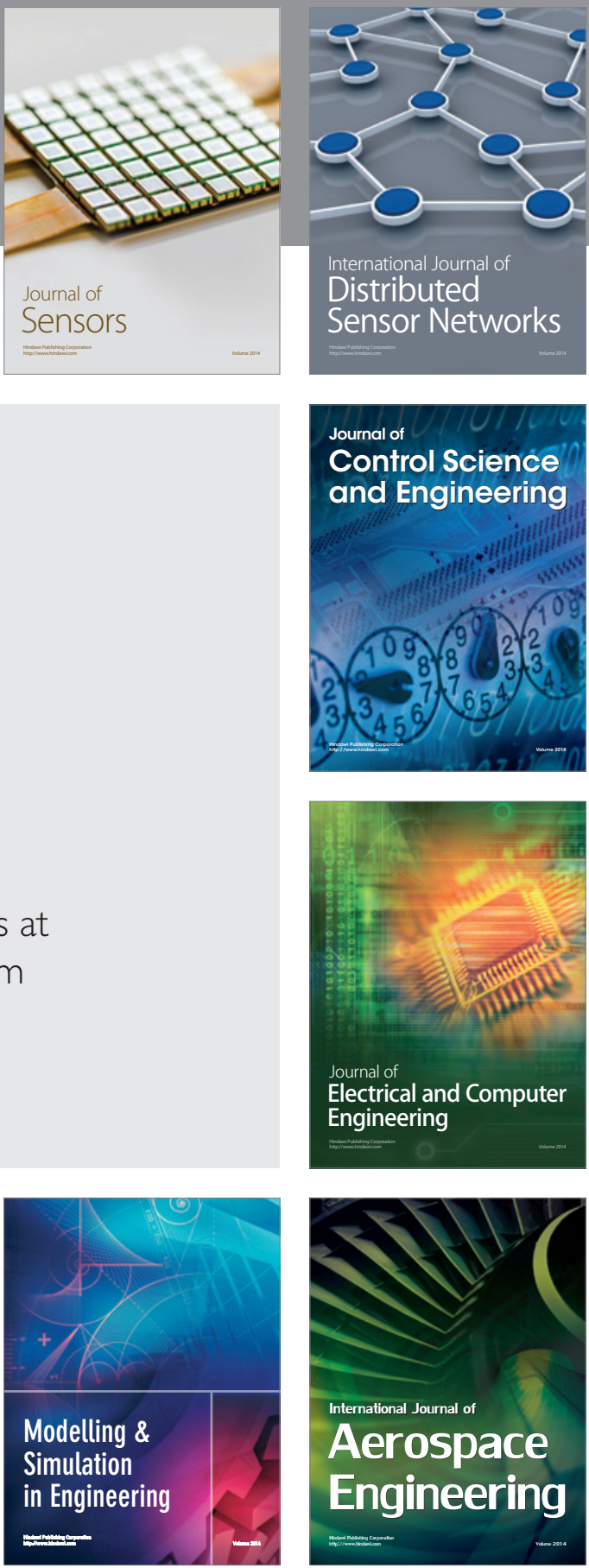

Journal of

Control Science

and Engineering
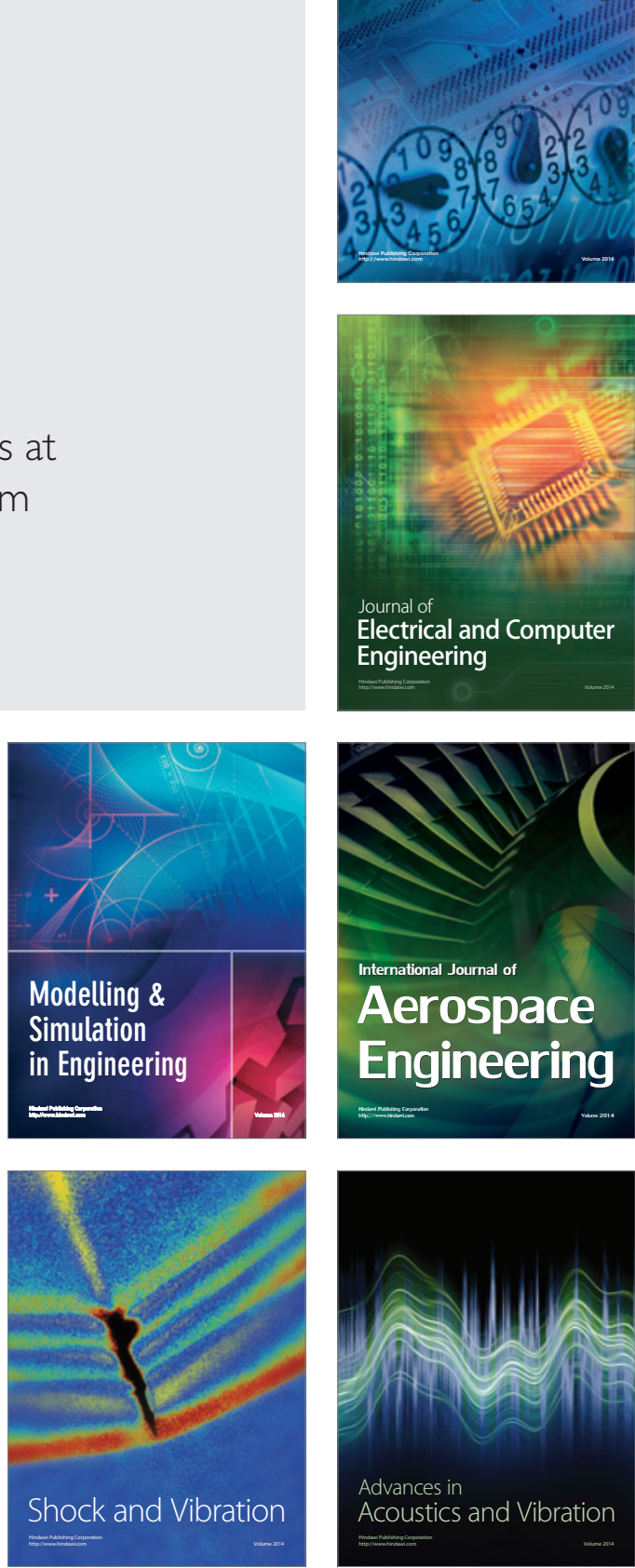